\title{
Occurrence of comorbid
}

substance use disorders among

acute psychiatric inpatients at

Stikland Hospital in the Western

\section{Cape, South Africa}

\section{Weich, W Pienaar}

Stikland Hospital and Department of Psychiatry, University of Stellenbosch, South Africa

\begin{abstract}
Objective: Little is known about the epidemiology of substance use disorders (SUD) among psychiatric inpatients in the Western Cape, South Africa. Therefore, this study was conducted to examine the prevalence of SUD among acute adult psychiatric inpatients at Stikland Hospital, one of three state acute psychiatric hospitals in the Western Cape. Method: A prospective descriptive prevalence survey was undertaken over a three-month period. During this period, data was collected on psychiatric patients ( $N=298)$ who were hospitalized in the acute psychiatric wards at Stikland. This included patient demography, psychiatric and substance use history. Urine was also collected and analyzed for substances commonly abused in the Western Cape. Results: A co-morbid SUD (abuse or dependence) was diagnosed in 51\% of patients. In addition, a diagnosis of a substance-induced psychiatric disorder was made in $8 \%$ of these patients, $1 \%$ of who was diagnosed with a substance-induced mood disorder, while $7 \%$ was diagnosed with a substanceinduced psychotic disorder. Patients diagnosed with a co-morbid SUD were younger than those without a SUD and more likely to have been involuntary admissions. These patients also displayed more violence prior to admission that contributed to their admission and were more likely to have used cannabis or methamphetamine as their preferred drug of abuse. Only a small group of patients had documented evidence of any prior interventions for their SUD. Conclusion: SUD are prevalent among psychiatric inpatients and contribute to their morbidity. This has implications for staff training and service development.
\end{abstract}

Key words: Substance use; Prevalence; Psychiatric inpatients, Dual diagnosis

Received: 01-04-2008

Accepted: 08-09-2008

\section{Introduction}

Research has shown that a complex association exists between mental and substance use disorders (SUD). Mentally ill patients may have impaired judgment, which may instigate drug use to self-medicate psychiatric symptoms. Alternatively, some drug addicts may develop mental disorders as a result of drug use. The co-morbid occurrence of mental and SUD in patients may also be coincidental. Furthermore, it is also possible that in some patients, the mental disorder and substance use might have a common underlying etiological cause. ${ }^{1}$

\section{Correspondence:}

Dr L Weich

Department of Psychiatry, PO Box 19063, Tygerberg 7505, South Africa

email: lizew@sun.ac.za
In general, patients with psychiatric disorders have an increased incidence of SUD when compared to the general population. ${ }^{2}$ Several studies have been undertaken on the prevalence of comorbid SUD amongst patients with mental illness. These studies have shown that rates of current SUD in psychiatric inpatients have ranged from 12 to $65 \%$ and from $48 \%$ to $64 \%$ for lifetime substance abuse or dependence..$^{3,4,5,6,7}$ Results of these studies were however inconsistent and influenced by variables such as the study population and sample size, as well as the diagnostic criteria that were used. Therefore, the large variance across different settings highlights the need for local surveys to explore the extent and nature of problems related to dual diagnosis.

Co-morbid SUD among mentally ill patients are typically coupled with a wide range of negative outcomes, compared with non-substance abusing patients..$^{89}$ For example, these 
patients are more likely to exhibit behavioural problems such as aggression that may lead to violent offences and increased rates of homicide. In addition, there are also higher rates of medication non-compliance, relapse and re-hospitalization, more carer distress, more homelessness and HIV infection, as well as an increased prevalence of suicide in this patient group. ${ }^{10,11,12,13}$ Other negative outcomes include higher treatment costs and a greater tendency to experience major impairments e.g., unemployment, financial problems, social isolation and interpersonal conflicts, when compared to individuals with only one type of disorder. ${ }^{14,15,16,17,18,19,20,21,22,23}$

Research has also shown that clients with both mental health and SUD have difficulties in accessing treatment for both their problems. ${ }^{24}$ Separately run substance and mental health services often do not adequately meet their unique needs. ${ }^{25}$ Clinicians increasingly perceive the disorders of these patients as two primary disorders that interact and affect the course of each other so closely that both require simultaneous treatment by one specialized, integrated service. ${ }^{26,27,28}$

Despite anecdotal evidence of an increase in the prevalence of dual diagnosed patients among psychiatric patients in the Western Cape, no accurate epidemiological studies for the prevalence of the problem exist. Concurrently, there is also no service that caters for the unique needs of these patients. Therefore, research is necessary to plan effective future services.

The objective of this study was thus to estimate the prevalence of current SUD (substance abuse and dependence) among psychiatric admissions to Stikland hospital, one of three dedicated state psychiatric facilities in the Western Cape. Further objectives were to examine variables such as demographic data, re-admission rates and primary psychiatric diagnosis of dually diagnosed clients compared to singly diagnosed clients, to estimate the prevalence of primary substance-induced psychiatric disorders and to identify the preferred drugs of abuse among this

\section{Method}

\section{Study design and population}

A prospective descriptive prevalence survey was undertaken. Study participants included all acute adult (18 -65 years) psychiatric patients admitted to Stikland Hospital over a 3month period. Patients admitted to the substance disorder units (pure substance disorders) were excluded from the study.

\section{Measurements}

On admission, each patient admitted during the study period was allocated a study number to which all study information was linked. This was done to maintain anonymity of patients. For each admission, the designated ward doctor completed a data sheet that included information on demographic data, patient admission information (e.g. voluntary or compulsory, first or re-admission, whether violence contributed to admission etc.), substance use history (including whether collateral history about substance use was obtained from relatives or friends) and the multidisciplinary team's consensus working psychiatric diagnoses. This data sheet was completed at discharge or one month after admission for patients who had not been discharged by one month. In addition, urine samples was collected from each patient immediately after admission and screened for cannabis, cocaine, opiates, methamphetamine and methaqualone. These illicit substances are the most frequently abused in the Western Cape. ${ }^{28}$ Analysis of the urine samples was done at the Tygerberg Toxicology Laboratory.

\section{Data analysis}

Data was analysed using Statistica computer software, version 7.1 (Statsoft, Inc., Oklahoma, USA [www.statsoft.com]).

Percentages and counts are presented as categorical variables. For these variables, descriptive statistics such as minimum and maximum, means ( \pm standard deviations [SD]) and 95\% confidence intervals (95\% CI) were computed. Correspondence analysis was used to assess relationships between two categorical data ranges. The chi-square $\left(\chi^{2}\right)$ test was used to determine the relationship between general categorical data and groups with or without comorbid SUD. For continuous data, One-way ANOVA and Mann-Whitney U- tests were used.

\section{Ethics}

Ethical approval was obtained from the Committee for Human Research of the Faculty of Health Sciences, University of Stellenbosch and the Superintendent of Stikland Hospital. International ethical norms and standards were strictly adhered to at all times.

\section{Results}

Demographic and admission data

Patient demographic data is summarised in Table I. The duration since previous admission is summarized in Table II. Results of the consensus working psychiatric diagnosis of the

\begin{tabular}{|l|l|}
\hline \multicolumn{2}{|l|}{ Table I: Study group characteristics (N= 298) } \\
\hline Age: Mean yrs (SD, 95\% Cl) & $34.6( \pm 25.4,33.3-35.9)$ \\
\hline Gender: Male, N (\%) & $160(54)$ \\
\hline $\begin{array}{l}\text { Legal status: } \\
\text { Involuntary admissions, N (\%) }\end{array}$ & $215(73)$ \\
\hline Readmissions, N (\%) & $207(70)$ \\
\hline $\begin{array}{l}\text { Number of prior admissions: } \\
\text { Mean (SD) } \\
\text { Median (minimum, maximum) }\end{array}$ & $\begin{array}{l}2.2( \pm 10.8) \\
1(0,13)\end{array}$ \\
\hline $\begin{array}{l}\text { Contribution of violence to admission, N (\%) } \\
124(43)\end{array}$ \\
\hline
\end{tabular}

\begin{tabular}{|c|c|}
\hline DURATION SINCE LAST ADMISSION & NUMBER OF PATIENTS N (\%) \\
\hline First admission & 89 (29.9) \\
\hline$<7$ days & $5(1.7)$ \\
\hline 7 days $-\leq 1$ month & $13(4.4)$ \\
\hline$>1$ month $-\leq 3$ months & $22(7.4)$ \\
\hline$>3$ months - $\leq 1$ year & $49(16.4)$ \\
\hline$>1-\leq 2$ years & $56(18.8)$ \\
\hline$>2$ years & $53(17.8)$ \\
\hline Missing data & $11(3.7)$ \\
\hline
\end{tabular}




\begin{tabular}{|c|c|c|c|}
\hline DIAGNOSTIC CLUSTER & $N(\%)$ & DIAGNOSIS WITHIN CLUSTER & $N(\%)$ \\
\hline Primary psychotic disorders & $114(38.3)$ & $\begin{array}{l}\text { Schizophrenia } \\
\text { Schizoaffective } \\
\text { Shizophreniform } \\
\text { Psychotic disorder NOS } \\
\text { Delusional disorder } \\
\text { Brief psychotic episode }\end{array}$ & $\begin{array}{l}85(28.5) \\
15(5) \\
8(2.7) \\
3(1) \\
2(0.7) \\
1(0.3)\end{array}$ \\
\hline Primary mood disorders & $96(32)$ & $\begin{array}{l}\text { Bipolar disorder } \\
\text { Major depressive disorder }\end{array}$ & $\begin{array}{l}60(20.1) \\
36(12.1)\end{array}$ \\
\hline Substance induced disorders & $23(7.7)$ & $\begin{array}{l}\text { Substance induced psychotic disorders } \\
\text { Substance induced mood disorders } \\
\text { Substance induced anxiety disorders }\end{array}$ & $\begin{array}{l}20(6.7) \\
3(1) \\
0\end{array}$ \\
\hline $\begin{array}{l}\text { Adjustment disorders } \\
\text { Disorders due to general } \\
\text { medical condition (GMC) }\end{array}$ & $\begin{array}{l}19(6.7) \\
14(4.7)\end{array}$ & $\begin{array}{l}\text { n/a } \\
\text { Psychotic disorder due to GMC } \\
\text { Dementia } \\
\text { Cognitive disorder due to GMC } \\
\text { Mood disorder due to a GMC } \\
\text { Personality changes due to GMC Delirium } \\
\text { Anxiety disorder due to GMC }\end{array}$ & $\begin{array}{l}9(3) \\
2(0.67) \\
1(0.3) \\
1(0.3) \\
1(0.3) \\
0\end{array}$ \\
\hline Primary anxiety disorders & $6(2)$ & $\begin{array}{l}\text { Post Traumatic Stress Disorder } \\
\text { Obsessive Compulsive Disorder } \\
\text { Panic disorder } \\
\text { Generalised Anxiety Disorder } \\
\text { Acute Stress Reaction } \\
\text { Social Anxiety Disorder } \\
\text { Specific phobia } \\
\text { Anxiety disorder NOS }\end{array}$ & $\begin{array}{l}4(1.3) \\
1(0.3) \\
1(0.3) \\
0 \\
0 \\
0 \\
0 \\
0\end{array}$ \\
\hline Personality disorders & $5(1.6)$ & $\begin{array}{l}\text { Cluster A } \\
\text { Cluster B } \\
\text { Cluster C }\end{array}$ & $\begin{array}{l}0 \\
5(1.7) \\
0\end{array}$ \\
\hline $\begin{array}{l}\text { Other } \\
\text { No diagnosis made } \\
\text { Missing data }\end{array}$ & $\begin{array}{l}4(1.3) \\
4(1.3) \\
13(4.4)\end{array}$ & $\begin{array}{l}n / a \\
n / a \\
n / a\end{array}$ & \\
\hline
\end{tabular}

\section{Table IV: Self-reported drugs of abuse within study population $(\mathrm{N}=298)$}

\begin{tabular}{|l|l|l|}
\hline SUBSTANCE & $\begin{array}{l}\text { NUMBER STATING } \\
\text { PRIMARY (PREFERRED) } \\
\text { DRUG OF ABUSE } \\
\text { N (\%) }\end{array}$ & $\begin{array}{l}\text { NUMBER WHO HAVE } \\
\text { USED THIS DRUG IN } \\
\text { THE PREVIOUS SIX } \\
\text { MONTHS N (\%) }\end{array}$ \\
\hline Cannabis & $81(27)$ & $118(40)$ \\
Alcohol & $68(23)$ & $93(31)$ \\
Amphetamine/ & $38(13)$ & $62(20)$ \\
Methamphetamine & & $12(4)$ \\
Cocaine/crack cocaine & $4(1)$ & $28(9)$ \\
Methaqualone & $2(1)$ & $10(3)$ \\
Opioids & $3(1)$ & $8(2)$ \\
Benzodiazepines & $5(2)$ & $1(0.3)$ \\
Other stimulants & 0 & $1(0.3)$ \\
Volatile solvents & 0 & $5(2)$ \\
Ecstasy (MDMA) & 0 & $1(0.3 \%)$ \\
Hallucinogens & 0 & \multicolumn{1}{|l}{} \\
\hline
\end{tabular}

multidisciplinary treatment team, that included a consultant psychiatrist, are summarized in Table III. A primary substanceinduced disorder was diagnosed in $8 \%$ of the patients admitted during the study period. Of these patients, 1\% was diagnosed with mood disorders, while $7 \%$ was diagnosed with psychotic disorders.

\section{Table V: Results of urine drug testing performed on study} population $(n=298)$

\begin{tabular}{|l|l|}
\hline DRUG TESTED & $\begin{array}{l}\text { NUMBER OF POSITINE TESTS } \\
\text { N (\%) }\end{array}$ \\
\hline Cannabis & $71(23.8)$ \\
Methamphetamine & $22(7.4)$ \\
Cocaine & $2(0.7)$ \\
Opiates & $19(6.4)$ \\
Methaqualone & $16(5.4)$ \\
\hline TOTAL NUMBER OF POSITIVE TESTS & 130 \\
\hline
\end{tabular}


Data on the self-reported substances of abuse along with the preferred drug of choice used in the six months prior to admission is summarized in Table IV, while the results of the urine drug testing is documented in Table V.

\section{Comorbidity}

Sixty-seven (23\%) patients met DSM-IV-R diagnostic criteria for current substance abuse on self-report and 71 (24\%) met the criteria for current substance dependence. Twenty-six (9\%) reported a previous history of substance dependence that was currently in remission. Collateral substance history was documented in 164 (79\%) of patients. In these cases, dependence was confirmed in 91\% of cases and abuse in $82 \%$ of cases. In most cases, there was no disagreement whether there was a SUD, but rather a disagreement in the extent of the problem (i.e. abuse vs. dependence). The total number of patients with a consensus diagnosis of a co-morbid SUD, i.e. either substance abuse or dependence on self-report, or obtained via collateral history, was 152 (51\%).

\section{Associated findings}

Of the patients with a diagnosis of comorbid SUD, 72\% were male, which was significantly more than the $27 \%$ females which has a comorbid SUD $\left(\chi^{2}\right.$ test, $\left.p<0.01\right)$. The age of patients with SUD was significantly younger (30.7 \pm 9.98 , 95\% CI: 29.0 -32.3; Mann Whitney U, p<0.01) compared to those without SUD (38.9 \pm 10.8, 95\% CI: 37.1-40.7). The highest rates of SUD were found in Belhar, Bishop Lavis, Elsiesrivier,

Kraaifontein, Paarl and Vredendal areas.

The number of patients with SUD that were involuntary admissions (81\%), was significantly ( $\chi^{2}$ test, $\left.p=0.0194\right)$ more than those without SUD (65\%). Also, patients with SUD were not likely to have had more previous admissions than patients without SUD (2.1 \pm 0.2 admissions for patients without SUD, vs. $2.2 \pm 0.2$ admissions for patients with SUD; Mann Whitney U, p $=0.83$ ). Patients were more likely ( $\chi^{2}$ test, $\left.p=0.00001\right)$ to be admitted compulsory if they stated that their primary substance of abuse were cannabis, alcohol or methamphetamine. Cannabis users had on average slightly more admissions than methamphetamine users (cannabis admissions: $2.6 \pm 2.8,95 \%$ CI: 1.9-3.3, vs. methamphetamine admissions: $1.3 \pm 1.5,95 \%$ CI: 0.6-1.8). In addition, patients with SUD (59\%) were significantly $\left(\chi^{2}\right.$ test, $\left.p<0.01\right)$ more likely to have violence contribute to their admissions than patients without SUD (26\%), especially cannabis and methamphetamine users.

Patients with substance-induced disorders and schizoaffective disorder had the strongest associations with a diagnosis of SUD, followed by bipolar disorder and schizophrenia. In contrast, patients with major depressive disorder and adjustment disorders had the lowest incidence of SUD. Methamphetamine use was highly associated with a diagnosis of substance-induced disorder, while cannabis use was associated with schizophrenia and schizoaffective disorders, and alcohol with major depressive disorder and adjustment disorders.

Very few patients had documented evidence of prior interventions for their substance use disorders. Of those, only eight (3\%) had received previous psycho-education, two $(0.7 \%)$ received detoxification, two $(0.7 \%)$ outpatient rehabilitation, and nine (3\%) had attended one inpatient rehabilitation program, while six (2\%) attended more than one rehabilitation program.

\section{Discussion}

Results of this study are comparable to results obtained by other international studies. . $^{3,5,5,6,7}$ Comorbid SUD were common among psychiatric inpatients and contributed to their morbidity. Admissions were more involuntary and were more associated with violence.

Interestingly, cannabis users had on average more admissions than methamphetamine users. A possible explanation for this is that cannabis use has been popular in the Western Cape for many years, but methamphetamine only became popular after 2002.

The high re-admission rates of patients with mental illness place a strain on hospital service delivery. This study however did not confirm international findings that comorbid substance disorders further increased re-admission rates. ${ }^{14}$ An explanation for this could be that this study was not designed to test this hypothesis and the 3-month data collection period was possible too short.

Results of the self-reported substances of abuse did not show a higher rate of alcohol abuse, although this was expected since alcohol is the most prevalent substance of abuse in South Africa. ${ }^{29}$ Rates of alcohol abuse might have been underestimated since alcohol is often not viewed as a substance of abuse by many, because it is legal and its use is the norm within a large part of our society. Alternatively, the perception that medication should not be used with alcohol may also have contributed to the relatively low number of patients reporting alcohol misuse.

The finding that only $7 \%$ of clients had a diagnosis of a substance-induced psychiatric disorder was surprisingly low. It is possible that this is an underestimation because patients might have mistakenly been diagnosed with schizophrenia. It is known that schizophrenia bears a resemblance to methamphetamine-induced psychosis and is also often chronic. $^{30,31}$ The abuse of methamphetamine is highly prevalent in the Western Cape and is the preferred drug of choice for patients in substance treatment programs in the Western Cape. $^{29}$

The low rate of documented interventions for SUD found in this study was of concern. It is possible that this is an underreporting because assessment of interventions for substance disorders is often not viewed as part of a psychiatric evaluation and therefore not documented. Alternatively, health workers perceive substance psycho-education as routine treatment for all their patients and may therefore not document these interventions. There is a need for increased training in the recognition and management of substance disorders among medical staff, especially staff working within the mental health field, including medical students and psychiatric registrars.

It is important that general psychiatric services need to place a greater emphasis on the management of these patients within mainstream psychiatry because of the high rate of comorbid SUD and the fact that SUD are very common. Furthermore, appropriate treatment services for patients with complex dual diagnosis need to be developed. This remains a challenge for most services due to limited resources, but needs to be taken into account when future mental health and substance services are planned. 


\section{Conclusion}

Certain weaknesses of this study are acknowledged. Firstly, no structured interview was performed. Psychiatric diagnoses were taken as a consensus working diagnosis and were not diagnosed using rating scales. Secondly, information necessary to diagnose a SUD may not always have been available due to the nature of the patients' illnesses and thus limited the estimation of prevalence of these disorders. The diagnoses of these cases were clarified by obtaining information on collateral history on substance use.

To conclude, substance use disorders are prevalent among psychiatric inpatients within the Western Cape, impact negatively on the patients and also add to the burden of service delivery. Few patients however receive interventions for their comorbid problem.

\section{Acknowledgements}

The authors would like to acknowledge the financial contributions by Stikland Hospital for drug testing, Prof. Martin Kidd for statistical analyses of data and the science writer, Karen Cloete, for assistance with manuscript editing.

\section{References}

1. Lehman AF, Myers CP, Corty EC. Assessment and classification of patients with psychiatric and substance abuse syndromes. Hosp Community Psychiatr 1989; 40: 1019-1030.

2. Regier DA, Farmer ME, Rae DS, Locke BZ, Keith SJ, Judd LL, et al. Comorbidity of mental disorders with alcohol and other drug abuse. Results from the Epidemiologic Catchment Area (ECA) Study. JAMA 1990; 264: 251 1-2518.

3. Brady K, Casto S, Lydiard RB, Malcolm R, Arana G. Substance abuse in an inpatient psychiatric sample. Am J Drug Alcohol Abuse 1991; 17: 389-397.

4. Cantwell R, Brewin J, Glazebrook C, Dalkin T, Fox R, Medley I, et al. Prevalence of substance misuse in first-episode psychosis. Br J Psychiatry 1999; 174: 150-153.

5. Havassy BE, Arns PG. Relationship of cocaine and other substance dependence to well-being of high-risk psychiatric patients. Psychiatr Serv 1998; 49: 935-940.

6. Lehman AF, Myers CP, Corty E, Thompson JW. Prevalence and patterns of "dual diagnosis" among psychiatric inpatients.. Compr Psychiatry 1994; 35: 106-11

7. Dixon L, Haas G, Weiden PJ, Sweeney J, Frances AJ. Drug abuse in schizophrenic patients: clinical correlates and reasons for use. Am J Psychiatry 1991; 148: 224-230.

8. Angermeyer MC. Schizophrenia and violence. Acta Psychiatr Scand Suppl 2000; 102: 63-67.

9. Soyka M. Substance misuse, psychiatric disorder and violent and disturbed behaviour. Br J Psychiatry 2000; 176: 345-350.

10. Swartz MS, Swanson JW, Hiday VA, Borum R, Wagner HR and Burns $B J$. Violence and severe mental illness: the effects of substance abuse and non adherence to medication. Am J Psychiatry 1998; 155: 226-231.

11. Drake RE, Brunette MF. Complications of severe mental illness related to alcohol and drug use disorders. In: Galanter M eds, The consequences of alcohol. New York (NY): Plenum, 1998: 285-299. (Recent developments in alcoholism; vol 14).

12. Hiroeh U, Appleby L, Mortensen PB, Dunn G. Death by homicide, suicide, and other unnatural causes in people with mental illness: a population-based study. Lancet 2001; 358: 2110-2112.

13. Bartels SJ, Drake, RE, Wallach, MA. Long-term course of substance use disorders among patients with severe mental illness. Psychiatr Serv 1995; 46 (3): 248-251.

14. Brown RA, Monti PM, Myers MG, Martin RA, Rivinus T, Dubreuil ME, et al. Depression among cocaine abusers in treatment: relation to cocaine and alcohol use and treatment outcome. Am J Psychiatry 1998; 155 (2): 220-225

15. Case N. The dual-diagnosis patient in a psychiatric day treatment program: a treatment failure. J Subst Abuse Treat 1991; 8(1-2): 6973.

16. Carroll KM, Power ME, Bryant K, Rounsaville BJ. One-year follow-up status of treatment-seeking cocaine abusers: psychopathology and dependence severity as predictors of outcome. J Nerv Ment Dis 1993; 181 (2): 71-79.

17. McLellan AT, Luborsky L, Woody GE, O'Brien CP, Druley KA. Predicting response to alcohol and drug abuse treatments. Role of psychiatric severity. Arch Gen Psychiatry 1983; 40 (6): 620-625.

18. Rounsaville BJ, Dolinsky ZS, Babor TF, Meyer RE. Psychopathology as a predictor of treatment outcome in alcoholics. Arch Gen Psychiatry 1987; 44 (6): 505-513

19. Rounsaville BJ, Kosten TR, Weissman MM, Kleber HD. Prognostic significance of psychopathology in treated opiate addicts: a 2.5-year follow-up study. Arch Gen Psychiatry 1986; 43 (8): 739-745.

20. Dickey B, Azeni H. Persons with dual diagnoses of substance abuse and major mental illness: their excess costs of psychiatric care. Am J Public Health 1996: 86 (7): 973-977.

21. Hoff RA, Rosenheck RA. Long-term patterns of service use and cost among patients with both psychiatric and substance abuse disorders. Med Care 1998; 36 (6): 835-843.

22. Hoff RA, Rosenheck RA. The cost of treating substance abuse patients with and without comorbid psychiatric disorders. Psychiatr Serv 1999; 50 (10): 1309-1315

23. Ridgely S, Goldma, HH, Willenbring M. Barriers to the care of persons with dual diagnoses: organizational and financing issues. Schizophr Bull 1990; 16: 123-132.

24. Drake RE, Mueser KT, Brunette MF, MC Hugo GJ. A review of treatments for clients with severe mental illness and co-occurring substance use disorder. Psychiatr Rehabil J 2004; 27:360-374

25. Osher FC, Drake RE. Reversing a history of unmet needs: approaches to care for persons with co-occurring addictive and mental disorders. Am J Orthopsychiatry 1996; 66 (1): 4-11.

26. Drake RE, Mueser KT, Clark RE, Wallach MA. The course, treatment, and outcome of substance disorder in persons with severe mental illness. Am J Orthopsychiatry 1996; 66(1): 42-51.

27. Minkoff K. An integrated treatment model for dual diagnosis of psychosis and addiction. Hosp Community Psychiatry 1989; 40: 1031-1036.

28. Minkoff K. Best practices: developing standards of care for individuals with co-occurring psychiatric and substance use disorders. Psychiatr Serv 2001; 52: 97-599.

29. SACENDU Update, Phase 20, 2006.

30. Segal DS, Janowsky DS. Psychostimulant-induced behavioural effects: possible models for schizophrenia. In Lipton MA, DiMascio A, Killam KF, eds, Psychopharmacology. A Generation of progress. New York: Rave Press, 1978:1113-1123.

31. Iwanami A, Sugiyama A, Kuroki $N$, Toda S, Kato $N$, Nakatani $Y$, et al. Patients with methamphetamine psychosis admitted to a psychiatric hospital in Japan. A preliminary report. Acta Psychiatr Scand. 1994; 89(6): 428-432. 